\title{
Workplace Conflict Manifestations and Turnover Intentions of Employees of Hospitality Organizations in Enugu Metropolis, South - East Nigeria
}

\author{
Okafor, Lawrence Chima Ph.D ${ }^{1}$, Okoye, Victor Ifesinachi ${ }^{2}$ \\ ${ }^{l}$ Department of Business Management Ebonyi State University, Abakaliki. \\ ${ }^{2}$ Department of Business Administration, Institute of Management and Technology (IMT), Enugu.
}

\begin{abstract}
This study centered on Manifestations of Workplace Conflict and Employee Turnover Intentions. Abusive Supervision, Workplace Mobbing, Workplace Ostracicm and Employee Turnover Intentions with respect to restaurants in Enugu metropolis formed the focus of the study. Structural Equation Modeling was used for testing the hypotheses. The findings revealed that Abusive Supervision was significantly related to Employee Turnover Intention(Standardized Coefficient $=0.944, p<0.05$ ). Workplace Mobbing was not significantly related to Employee Turnover Intention (Standardized Coefficient $=-0.553, p>0.05$ ). Also, existence of relationship was found between Workplace Ostracism and Employee Turnover Intention(Standardized Coefficient=0.318, $p<0.05$ ). On the strength of these findings, we recommend amongst others the need for training and re-training of owners and managers of these firms to update their supervisory skills as well as the need to review and possibly update laws relating to employment in Nigeria.
\end{abstract}

\section{Background Of The Study:}

From time immemorial, hospitality firms have provided invaluable services to humanity. Increasing urbanization, the rising need for excellence coupled with the demands of globalization are all acting in concert to making demands for services of hospitality firms a routine if not a practice by many individuals and corporate organizations.

From the 1940's when Enugu became a regional headquarters (courtesy of the Richard constitution) till date, the city has witnessed tremendous growth in size, structure and population. Intensive rural-urban migration, upsurge in the number of higher institutions (students population of these institutions no doubt have accentuated the increasing population of the city), increasing economic activities as well as the growing recognition and influence of the city as the political hub and headquarters of South - East, Nigeria are some of the identified correlates and determinants of the size, structure, and population of Enugu - with implications for the demands for the services of hospitality organizations.

With an increasing population and the need to satisfy some basic needs, the emergence of hospitality organizations was no coincidence. Where an average Nigerian spends $72.9 \%$ of his/her earnings on food as reported by Uche (2011), it is conceivable that several hospitality firms will spring up in their different forms, names and sizes providing sometimes similar and sometimes different services. Unarguably, these firms/organizations provide employment to a large number of people (both skilled and unskilled). This is in addition to their being sources of revenue to government, profit to their owners, an index of economic growth, with a contribution to the Gross Domestic Product (G.D.P.).

However, observations by the researchers supplemented by public opinion show a persistent increase in the rate of employee turnover amongst restaurants (these shall be the focus of this study) in Enugu metropolis. When an employee(s) move beyond organizational boundaries, it is termed employee turnover (Okafor, 2014). For Fapohunda (1980), labour turnover is a flow of man power into and out of the organization, while the Webster's Comprehensive Dictionary (2004) captures employee turnover as the rate at which persons hired by a given establishment within a given period are replaced by others. Meanwhile, labour turnover is an index of the stability of the work force. Writers are all agreed that the rate of turnover provide a graphic illustration of the turbulence within the organization, as a high rate of attrition can destabilize a business, de-motivate those who attempt to maintain levels of service and output against a background of vacant posts, inexperienced staff, and general discontent (Armstrong, 2005). Simply put, increasing rate of employee turnover has implications for organization performance both in terms of cost of operations and possibly relationship management.

Our preliminary investigation show a high attrition rate occasioned partly by workplace conflict manifested in the forms of abusive supervision, mobbing and ostracism. Conventionally, conflict is a fact of organization life, inevitable and unavoidable. Following the interactionist viewpoint, some level of conflict is even suggested (Okafor, 2016). However, an increasing level of conflict is not only dysfunctional but may be detrimental hence, the need to sufficiently and adequately handle its predisposing factors. 
Extant literature on employee turnover are replete with the consequences of turn over intention and actual turnover. In the main, turnover intention is adjudge to be the most immediate and stronger antecedent of turnover (mobley etal.., 1979), employee turnover is a threat to the sustainability of firms, increase replacement and training costs, result in inefficiency in services rendered to customers, decline in patronage, loss of customers who may desire the services of the departed employee(s) (Dawley and Andrew 2012, Rahman and Naz 2013, Okafor, 2014).

The preceding paragraph is a pointer to the fact that both intention and actual turnover of employee(s) can be seen as predictor as well as correlate of many organizational variables. Ignoring the consequences of employee turnover intention may be detrimental to an organization. It becomes expedient that workplace conflict manifestation (in the forms of Abusive supervision(AS),Mobbing(MO), and Ostracism (OS) which may have significant relationship with turnover intention be investigated especially as it relates to restaurants operating in Enugu metropolis, South-East Nigeria. The concern of these authors is that a high attrition rate presents a problem that have the potency of reducing income, resulting in revenue loss as well as declining profit - with possible negative implications on the entire hospitality industry of Enugu State.

\section{Objectives Of The Study}

Essentially, the study seeks to explore relationships between conflict manifestations and employee turnover intentions. Specifically, we shall

i. Examine the extent of relationship between abusive supervision and employee intention to leave.

ii. Investigate the influence of workplace mobbing on employee intention to leave an organization.

iii. Investigate the extent to which workplace ostracism affects employee intention to leave restaurants in Enugu metropolis.

\section{Research Hypothesis}

For the purpose of this investigation, we raise the following hypothesis as a guide.

$\mathrm{H}_{1}$ There is a significant relationship between abusive supervision and employee turnover intention in restaurants in Enugu Metropolis.

$\mathrm{H}_{2} \quad$ Workplace mobbing is related to turnover intention of employees of restaurants in Enugu metropolis

$\mathrm{H}_{3}$ A relationship exists between workplace ostracism and employee turnover intention in restaurants in Enugu metropolis.

\section{Literature Review}

Conflict is a fact of organization life, sometimes inevitable, and unavoidable. Conflict is a reality and like for all realities there have been attempts at defining, explaining and explicating it (them). In furtherance of these attempts, we now have different definitions and theories of conflict. Robbins (2005) sees conflict as a process that begins when one party perceives that another party has negatively affected or about to negatively affect something that the $1^{\text {st }}$ party cares about. For Anugwom (2007), conflict is premised on incompatibility of goals arising from opposing behavior ... with the intention to obstruct the achievement of some other person's goal(s).Good as these definitions are, they failed in explaining the many variables of conflict. To say that conflict is only perceptual or that they are products of opposing behaviours without recourse to their manifestation may be misleading. Authors have also labored to justify conflicts. Amongst the many reasons given as justification for conflict include limited resources, differences in goals, perception, orientation, race, religion and background. Other reasons are power and authority relationships as well as other institutional induced forces (Achir, 2014, Anele 2014). Okafor, 2016). A mere identification of the forces that give rise to conflict is insufficient as they may not provide enough grounds for their management.

In similar manner, there have been efforts to explicate and explain the reality of conflict. Put differently, authors have tried to theorize in relation to conflict. For now, three (3) dominant theories are found in contemporary management literature. The first referred to as the traditional theory, sees all conflicts as bad and must be dealt with at all costs. This view point is idealistic as it is proven that a world without conflict has never, does not and will never exist. The second termed human relation approach is a more realistic exposition on conflict. It subscribes to the idea that that which cannot be cured must be endured. Therefore, managers are advised to put in place appropriate mechanism and measures to handle and manage conflicts. (Ajah, 2007, Okafor, 2016) The third viewpoint referred to as the interactionist viewpoint (a positive inclination), thinks that not all conflicts are bad, that some level of conflict is actually needed as such minimal level(s) of conflict may confer some benefits to an organization in ways not intended.

Good exposition visa - vis definitions, causes and theories of conflict, but these positions failed in addressing the conflict manifest variables and their relationships with employees turnover intentions especially in backward formations in dire need of optimizing operational efficiency of services oriented organizations. 
However this lacuna in research and literature regarding workplace conflict manifestations began to be filled by the works of Einarsen etal (2011), Barlett and Barlette (2011), Namie (2003) and Leymann (1996). Some of these works initially compartmentalized all workplace conflicts manifestations under bullying - a process in which an employee is subjected to frequent negative acts for a relatively long period of time by peers or superiors, against which defense or retaliation is hindered by the recognition of a formal or informal power balance (Einarsen etal, 2011). Over time, this omnibus categorization of workplace conflict manifestations began to give way for a more realistic categorization of these phenomena. Today, workplace conflicts are known to manifest in different forms to include abusive supervision, mobbing and ostracism.

Abusive Supervision (AS), following Tepper (2000) refer to subordinates perception of the extent to which their superiors engage in the sustained display of verbal and non verbal behaviours, excluding contacts. Manifestations of (AS) could be observed when a supervisor publicly ridicules a subordinate, blames subordinates for mistake(s) they did not make, and giving subordinates a silent treatment. Admittedly, subordinates may asses the degree of (AS) subjectively regarding their superior's behavior towards them (Hoobler and Brass, 2006), nevertheless, it has been described as a counterproductive behavior. However, a general preposition is that an enduring negative experience in the form of (AS), can make an employee evaluate the situation and question whether to remain in the employment relationship. Where likely injustice is perceived in a relationship after an (AS) experience, the employee may contemplate future mistreatment of the same kind, hence, a possible search of employment elsewhere.

Workplace mobbing represents a malicious attempt to force a person out of the workplace through psychological terror, unjustified accusations, humiliation, general harassment and emotional abuse. (Davenport etal.., 1999). Leymann and his associates had earlier in 1996 described mobbing as psychological terror at the workplace involving hostile and unethical communication initiated by individuals and directed in a systematic manner towards an individual, who, because of mobbing, is in a state of helplessness. No matter how conjectured, mobbing seen as a form of group behavior (distinguishing it from bullying that may imply individual acts") is a form of aggression exercised over a period of time by colleagues towards another, with the target in most cases finding it difficult to defend himself/ herself.

Managerial psychology literature is replete with perpetrators and targets of workplace mobbing. It is suggested by some authors that there are personality traits that typify perpetrators and targets. In the opinion of Davenport etal (1999), targets of mobbing tend to be trusting, cooperative, conscientious, high achievers and often loyal to the organization. Neumann and Baron (2004) submit that the perpetrators are perceived as authoritarian, manipulative, insensitive and psychopaths. The objects (victims) of the "attack" and the "attacker" (perpetrators) notwithstanding, mobbing has the capacity to negate the operational efficiency of an organization. Existing literature on the subject matter suggest consequences at both the organizational level and victim, and also social consequences. At the level of the organization, these consequences manifest in decrease effectiveness, which can lead to staff turnover. Mobbing actions on victims can result in low esteem, depression, insomnia, abnormal behaviours, withdrawal syndrome, loss of efficiency at work and stress. Generally, in organizations where mobbing occurs, disagreements appear, discomfort arises and employees search for an escape. (Blois and Hoel 2007, Carneso etal 2012, Bjorkelo, 2013).

Meanwhile, workplace ostracism has been conceived to mean the extent to which an individual perceived that he/she is ignored or excluded by others in the workplace (Feris etal, 2008). Referred to variously as social isolation, (Rook 1984), social exclusion (De wall etal (2009), peer rejection (Prinstein and Aikins (2004), workplace ostracism is a common and universal phenomenon, that transcends national and organizational boundaries as well as hierarchical levels. Examples of ostracism behaviours in workplaces include, with-holding needed and vital information, giving the cold shoulder or silent treatment, avoiding conversation and eye contact, avoiding handshakes, and other forms of greetings. Other aspects of ostracism identified by Robinson etal (2013) include, having one's greetings ignored, being excluded from invitations, noticing others go silent when one seeks to join them... An intent to disconnect and isolate, ... to disengage the target of ostracism from social interactions. Although the underlying reasons for ostracism in workplaces may remain ambiguous, the effects of such practices are painful, associated with a variety of detrimental, physical, psychological and work related consequences.

Good expositions one may say. However, in modern day organizations where team work and team spirit are emphasized, the practice of ostracism will be counterproductive. Whereas documented evidence exist as to the import of ostracism on organizational participants (in terms of mental and physical health), little research efforts have been directed in the search for a possible link between ostracism and employee turnover intension visa - vis hospitality firms in Enugu Urban, hence, this study. 


\section{Methodology}

The researchers sampled 225 restaurants in Enugu urban and purposively selected two employees from each restaurant as target respondents. Cross Sectional design was used in this study in which the researcher administered 450 questionnaires of which 400 copies were returned from the survey and analysed. The constructs used in this study were measured based on 5 point scale ranging from Strongly Agree to Strongly Disagree. Abusive Supervision was measured with the following items: My supervisor is rude to me, my supervisor makes negative comments about me to others, my supervisor expresses anger at me when he/she is momentarily mad for another reason, my supervisor puts me down in front of others. The following items were used to measure Workplace Mobbing; I am often interrupted by my colleagues during meetings, my colleagues often insult me at the workplace, they frequently yell and scream at me in the workplace, while workplace Ostracism was measured using the following: My greetings are seldom answered by my colleagues, values of my efforts are ofte taken for granted, on some occasions, when I walk into the midst of my colleagues, they will leave the area because of my presence. The researchers went further to measure Turnover Intention with the following items: I will leave this restaurant at the earliest possible opportunity, I am actively looking for an alternative job, I consider quitting my job.

\section{Data Analysis}

Structural Equation Modeling (SEM) was used for testing of hypotheses for this study. Our choice of SEM is anchored on the basis that it examines interrelationship expressed in a series of equations similar to a series of multiple regression equation. Hypothesis one proposed that abusive supervision is related to employee turnover intention in restaurants in Enugu urban. The result revealed a statistically significant relationship since the calculated $\mathrm{p}-$ value 0.004 was less than $0.05(\mathrm{p}<0,05)$, (table 1$)$.

Table 1 Regression Weights: (Group number 1 - Default model)

\begin{tabular}{|l|l|l|l|l|l|l|l|}
\hline & & & Estimate & S.E. & C.R. & P & Label \\
\hline TOI & $<---$ & ASUP & 2.040 & .716 & 2.850 & .004 & par_10 \\
\hline TOI & $<---$ & MOB & -.929 & .576 & -1.613 & .107 & par_11 \\
\hline TOI & $<---$ & OST & .303 & .092 & 3.280 & .001 & par_12 \\
\hline toi1 & $<---$ & TOI & 1.000 & & & & \\
\hline toi2 & $<---$ & TOI & .623 & .083 & 7.489 & $* * *$ & par_1 \\
\hline toi3 & $<---$ & TOI & .919 & .092 & 10.040 & $* * *$ & par_2 \\
\hline asup4 & $<---$ & ASUP & 1.000 & & & & \\
\hline asup3 & $<---$ & ASUP & 1.553 & .193 & 8.046 & $* * *$ & par_3 \\
\hline asup2 & $<---$ & ASUP & 1.375 & .173 & 7.935 & $* * *$ & par_4 \\
\hline asup1 & $<---$ & ASUP & 1.805 & .215 & 8.390 & $* * *$ & par_5 \\
\hline mob3 & $<---$ & MOB & 1.000 & & & & \\
\hline mob2 & $<---$ & MOB & 1.112 & .126 & 8.825 & $* * *$ & par_6 \\
\hline mob1 & $<---$ & MOB & 1.478 & .153 & 9.670 & $* * *$ & par_7 \\
\hline os3 & $<---$ & OST & 1.000 & & & & \\
\hline os2 & $<---$ & OST & 1.044 & .074 & 14.195 & $* * *$ & par_8 \\
\hline os1 & $<---$ & OST & .781 & .061 & 12.878 & $* * *$ & par_9 \\
\hline
\end{tabular}

Source: Researcher's Computation

Hypothesis two proposed that workplace mobbing is related to employee turnover intention in restaurants in Enugu urban, The result showed a non statistically significant relationship ( $\mathrm{p}>0.05)$. Hypothesis three proposed that a relationship exists between workplace ostracism and employee turnover intention in restaurants in Enugu urban. The result also revealed the presence of a statistically significant relationship. The standardized regression weights (table2), showed that one standard deviation increase in abusive supervision resulted in increase in employee turnover intention by 0.944 standard deviation. Further, one standard deviation increase in workplace mobbing brought about 0.533 standard deviation decrease in employee turnover intention. Interestingly too, one standard deviation increase in workplace ostracism resulted in 0.318 standard deviation increase in employee turnover intention.

Table 2 Standardized Regression Weights: (Group number 1 - Default model)

\begin{tabular}{|l|l|l|l|}
\hline & & & Estimate \\
\hline TOI & $<---$ & ASUP & .944 \\
\hline TOI & $<---$ & MOB & -.533 \\
\hline TOI & $<---$ & OST & .318 \\
\hline toi1 & $<---$ & TOI & .727 \\
\hline toi2 & $<---$ & TOI & .457 \\
\hline toi3 & $<---$ & TOI & .724 \\
\hline asup4 & $<---$ & ASUP & .520 \\
\hline asup3 & $<---$ & ASUP & .586 \\
\hline
\end{tabular}




\begin{tabular}{|l|l|l|l|}
\hline asup2 & $<---$ & ASUP & .572 \\
\hline asup1 & $<---$ & ASUP & .632 \\
\hline mob3 & $<---$ & MOB & .581 \\
\hline mob2 & $<---$ & MOB & .609 \\
\hline mob1 & $<---$ & MOB & .721 \\
\hline os3 & $<---$ & OST & .756 \\
\hline os2 & $<---$ & OST & .833 \\
\hline os1 & $<---$ & OST & .704 \\
\hline
\end{tabular}

Abusive supervision, workplace mobbing and workplace ostracism accounted for $52.5 \%$ of the variance in employee turnover intention. (Table 3).

Table 3 Squared Multiple Correlations: (Group number 1 - Default model)

Source: Researcher's Computation

\begin{tabular}{|c|c|}
\hline & Estimate \\
\hline TOI & .525 \\
\hline os1 & .495 \\
\hline os2 & .693 \\
\hline os 3 & .571 \\
\hline mob1 & .520 \\
\hline mob2 & .370 \\
\hline mob3 & .337 \\
\hline asup1 & .399 \\
\hline asup2 & .327 \\
\hline asup3 & .343 \\
\hline asup4 & .271 \\
\hline toi3 & .524 \\
\hline toi2 & .208 \\
\hline toi1 & .529 \\
\hline
\end{tabular}

Table 4 CMIN

\begin{tabular}{|l|l|l|l|l|l|}
\hline Model & NPAR & CMIN & DF & P & CMIN/DF \\
\hline Default model & 32 & 186.472 & 59 & .000 & 3.161 \\
\hline Saturated model & 91 & .000 & 0 & & \\
\hline Independence model & 13 & 1562.778 & 78 & .000 & 20.036 \\
\hline
\end{tabular}

Source: Researcher's Computation

The model revealed a chi-square result of $X^{2}=186.472$, (table).

Chi-square is one of the statistics used for measuring goodness of fit. Its objective is to determine the extent to which the estimated covariance is equal to the calculated covariance in the model. . In this study, it is 0.000 at degrees of freedom $(d f)=59$; Goodness of Fit Index $(\mathrm{GFI})=0.931$; Adjusted Goodness of Fit Index $($ AGFI $)=0.894($ table 5$)$

Table 5 RMR, GFI

\begin{tabular}{|l|l|l|l|l|}
\hline Model & RMR & GFI & AGFI & PGFI \\
\hline Default model & .054 & .931 & .894 & .604 \\
\hline Saturated model & .000 & 1.000 & & \\
\hline Independence model & .301 & .467 & .378 & .400 \\
\hline
\end{tabular}

The Comparative Fit Index $(\mathrm{CFI})=0.914$ and Incremental Fit Index $(\mathrm{IFI})=0.915$, (table6 ), while the Root Mean Square Error of Approximation $($ RMSEA) $=0.074$, (table 7 ).

Table 6 Baseline Comparisons

\begin{tabular}{|l|l|l|l|l|l|l|}
\hline Model & $\begin{array}{l}\text { NFI } \\
\text { Delta1 }\end{array}$ & $\begin{array}{l}\text { RFI } \\
\text { rho1 }\end{array}$ & $\begin{array}{l}\text { IFI } \\
\text { Delta2 }\end{array}$ & $\begin{array}{l}\text { TLI } \\
\text { rho2 }\end{array}$ & CFI \\
\hline Default model & .881 & .842 & .915 & .886 & .914 \\
\hline Saturated model & 1.000 & & 1.000 & & 1.000 \\
\hline Independence model & .000 & .000 & .000 & .000 & .000 \\
\hline
\end{tabular}

Source: Researcher's Computation

Table 7 RMSEA

\begin{tabular}{|l|l|l|l|l|}
\hline Model & RMSEA & LO 90 & HI 90 & PCLOSE \\
\hline Default model & .074 & .062 & .086 & .001 \\
\hline Independence model & .218 & .209 & .228 & .000 \\
\hline
\end{tabular}

Source: Researcher's Computation 
The above fit indices are adjudged moderate. The indicator variables show standardized regression weights greater than 0.5 except for indicator variable toi 2 which is 0.457 . These show a moderate convergent validity. Analysis of Moment Structures (AMOS) software, version 18 was used for SEM computations. The oval shaped constructs shown in the model are latent variables (constructs), while the rectangular shaped are observed variables (figure1). The latent constructs (ASUP) indicates Abusive Supervision, (MOB) indicates workplace mobbing, (OST) indicates workplace ostracism while (TOI) represents Turnover Intention Attached to Abusive supervision are four (4) indicators, Workplace Mobbing has three(3) indicators, also three indicators are attached to Workplace Ostracism while three(3) indicators are attached to Turnover Intention . Each indicator variable has an error term attached to it.

Figure 1.

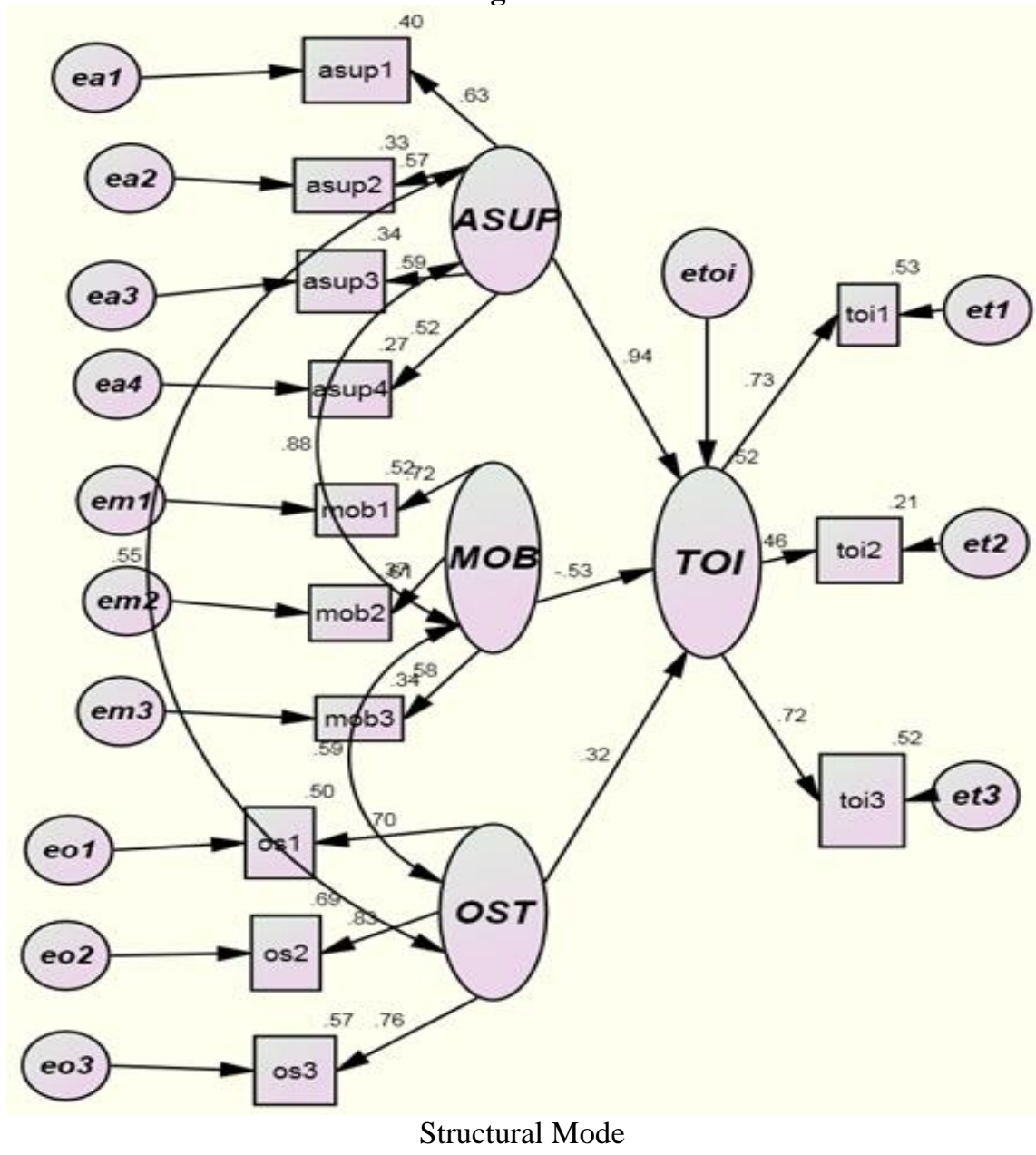

In summary, turnover Intention increased significantly as Abusive Supervision (ASUP) increased (standardized coefficient $=0.944, \mathrm{p}<0.05)$. Also, increased (OST) significantly increased (TOI), with standardized coefficient $=0.318, \mathrm{p}<0.05$. Further, increase in (MOB) did not significantly decrease (TOI), with standardized coefficient $=-0.533, \mathrm{p}>0.05$.

\section{Recommendations}

On the strength of the findings of this study, we recommend as follows

i. The Ministry of Trade in conjunction with that of Tourism establish mechanisms for upgrading the supervisory skills and knowledge of owners and managers of restaurants.

ii. There is need for review as to possibly update existing laws relating to employment generally in Nigeria.

iii. The Human Rights Commission is enjoined to investigate matters relating to human right abuses as to prosecute those found culpable. 


\section{References}

[1] Achiri, C.S (2014) Credibility, Leadership, and Crises Management. Journal of Leadership Studies 6 (3) $\mathrm{p}_{\mathrm{p}} 71-83$

[2] Ajah, A.A (2007) Basic concepts, issues and strategies of peace and conflict resolution. Nigerian African conflict case studies. Abuja: Centre for international and strategic studies in association with Keny and Brothers Int.

[3] Anele C.A, (2014) Industrial and Labour Relations. Enugu: Rhycekerex publishers.

[4] Anugwom, G.A (2007) Industrial Relations System in Nigeria. Enugu: Rhycekerex publishers.

[5] Armstrong, M (2005) A Handbook of Human Resources Management Practice. London: Kogan page.

[6] Barlett, J.E and Barlett M.E (2011) workplace bullying: An integrative literature review. Advances in Developing Human Resources; 13 (1) $\mathrm{p}_{\mathrm{p}} 69-84$

[7] Bjorkelo, B (2013) workplace bullying after whistle blowing: future research and implications. Journal of Management Psychology 28 (3) $\mathrm{P}_{\mathrm{p}}$ 306-323.

[8] Bloisi, W and Hoel, H (2007) Abusive work practices and bulling among chefs: A review of literature. International Journal of Hospitality Management 6 (27) $\mathrm{P}_{\mathrm{p}}$ 649-656.

[9] Carnero, A.M, Martinez, B and Rocio, S.M (2012) Mobbing and workers' health: Empirical Analysis for Spain. International Journal of Manpower 33 (3) 322-339.

[10] Davenport, N, Distter, S.R and Pursell, E.G (1999) Mobbing: Emotional Abuse in the American workplace. lowa, USA: Civil Society Publishing.

[11] Dawley, D.D and Andrews, M. (2012) Staying put off-the-job Embeddedness as a moderator of the relationship between on the-the -job Embeddedness and Turnover Intentions. Journal of Leadership and Organizational Studies 19(4) $\mathrm{P}_{\mathrm{p}} 140-1154$.

[12] Dewall, C.N, Twenge, J.M, Gitter, S.A and Baumeister C. (2009) It is the thought that counts : the role of hostile cognition in shaping aggressive responses to social exclusion, Journal of sociology and psychology 6 (8) $\mathrm{p}_{\mathrm{p}} 45-59$,

[13] Einarsen, S, Hoel, H, Zapf, D and Cooper, C (2011) Bulling and Harassment in the workplace: developments in theory, research and practice. $2^{\text {nd }}$ edition, Boca Raton: CRC Press.

[14] Fapohunda, E.R. (1980) what is behind labour Turnover? Journal of the Institute of personnel management of Nigeria 2(3) $\mathrm{P}_{\mathrm{p}}$ 17-22.

[15] Feris, D.L, Brown D. J, Berry, J.W and Lian, H (2008) The development and validation of the workplace ostracism scale. Association of psychologists 348-1366.

[16] Hoobler, J.M and Brass D.J (2006). Abusive supervision and family undermining as displaced aggression. Journal of Applied psychology 91, 1125-1133.

[17] Leymann, H (1996) The content and development of mobbing at work. European Journal of work and organizational psychology 5(2) $165-1184$

[18] Mobley, W. H, Griffith, H and Megline, B(1979). Review and conceptional analysis of the employee turnover process. Psychological bulletin 86,493 - 522

[19] Namie G (2003). The WBI 2003 Report on abusive work practices. Retrieved 10/19, 2013 from www.bullyinginstitue.organization .

[20] Okafor, L.C (2014) Labour policy influence on worker's discontent. evidence from tertiary health Institutions in Ebonyi State. Unpublished thesis submitted to the department of Business Management, EBSU Abakaliki.

[21] Okafor, L.C (2016) Conflict Management through conflict stimulation. Evidence from selected business concerns in South-East, Nigeria. GE - International Journal of Management Research, 4(4) $\mathrm{P}_{\mathrm{p}}$ 1-8.

[22] Prinstein, M.J and Aikins, J.W (2004) Cognitive Moderators of the longitudinal Association between Peer Rejections. Journal of Abnormal Child Psychology 3(2) $\mathrm{P}_{\mathrm{p}}$ 147-158.

[23] Rahman, W and Nazi Z (2013) "Employee Development and Turnover Intention: Theory validation" European Journal of Training and development 37(6) $\mathrm{P}_{\mathrm{p}}$ 564-579.

[24] Robins S.P. (2005) Organizational Behaviour, $11^{\text {th }}$ Edition. India: Prentice of India Private Ltd.

[25] Robinson S.L, O' Reilly and Wang, W (2013)' Integrated model of Workplace Ostracism. Journal of Management 3 (9) $p_{p} 203-23$

[26] Rook, K.S (1984), Promoting social bonding strategies for helping the lonely and socially isolated. American Psychologist 3 (9) $1389-1407$

[27] Tepper B.J (2000) Consequences of abusive supervision. Academy of Management Journal. 4 (3) $\mathrm{p}_{\mathrm{p}} 178-190$

[28] The New International Webster's Comprehensive Dictionary of English Language (2004) Encyclopedia Edition. Florida: Typhoon International Corp.

[29] Uche, M.N (2011) Steady growth of Nigeria retail food sector. Grain Report. Global Agriculture Information Network. 